Original article

\title{
Reproductive health practice of married women in the rural community
}

\author{
Shila Rani Das', Monowar Ahmad Tarafdar². Md. Saizuddin ${ }^{3}$, Nadia Begum ${ }^{4}$, Sultana Begum , \\ Mehruba Afreen ${ }^{6}$
}

\begin{abstract}
:
This cross sectional study of fifteen days' duration was conducted among Married women attending in OPD at Dhamrai Dhaka to know Reproductive Health Practice of Married Women in the Rural Community with a sample size of 100 following purposive sampling technique using pretested semi-structured questionnaire by face to face interview method after taking informed consent. Data were analyzed manually and by using computer. Only $39 \%$ respondents were found within age group 20-30 years and 33\% completed primary education. Majority the of respondents (79\%) were married. This study also found that $39 \%$ were housewives and majority $(56 \%)$ had poor monthly income $(\mathrm{TK}<10,000)$. Majority (78\%) of respondent's duration of married life less than or equal to 15 years. This study also revealed that (72\%) respondents were found having their first issue less than or equal to 25 years of age. About $40 \%$ respondents were found having two children. About $47 \%, 52 \% \& 25 \%$ respondents received advices on healthy diet, personal hygiene and cautions about drug uses respectively during antenatal period. Majority (84\%) of respondents were done USG on their routine antenatal care investigation. About $65 \%$ respondents delivered their last issue at hospital among them 55\% respondents last delivery conducted by qualified doctors. Majority $(85 \%)$ respondent received TT immunization and $71 \%$ respondents were not faced any complication in last delivery and $53 \%$ respondents were suffering from problems related to reproductive system and among them abortion (35\%), PPH (30\%) and perineal tear (20\%). Reproductive health practice was still worse among the rural community Effective strategies must be taken to improve reproductive health status of the rural women.
\end{abstract}

\section{Key words: Reproductive Health, Antenatal care, Morbidity pattern, Practice}

\section{Introduction:}

Reproductive Health (RH) is a state of complete physical, mental and social well-being (not merely the absence of disease and infirmity) in all matters relating to the reproductive system and its functions and processes. ${ }^{1}$ Women reproductive health is relatively a new area of health intervention in Bangladesh and becomes an important issue. Among the women, married adolescents are particularly vulnerable regarding reproductive health problem in Bangladesh. ${ }^{3}$ The reproductive health approach is concerned not only with pregnancy related health issue, but also with health and human right issues. ${ }^{4}$ Reproductive rights embrace certain human rights that are already recognized in national laws, international human rights documents and other consensus documents. ${ }^{5}$ Reproductive and sexual health rights are rights of all people, regardless of age, gender and other characteristics. ${ }^{6}$ Women have the right to the enjoyment of the highest attainable standard of physical and mental health and is vital to their life and well-being and their ability to participate in all areas of public and private life. ${ }^{7}$ Reproductive rights must be protected, promoted and filled if sexual and reproductive health outcomes are to be improved, particularly for the poor and vulnerable. ${ }^{8}$ The socioeconomic and demographic characteristics of people in a particular society are likely

1. Associate Professor, Department of Community Medicine, Z H Sikder Woman's Medical College, Dhaka, Bangladesh. Email:dr.shila@yahoo.com, Mobile - 01911183906

2. Professor and Head, Department of Community Medicine, Z H Sikder Woman's Medical College, Dhaka, Bangladesh.

3. Professor, Department of Community Medicine, Z H Sikder Woman's Medical College, Dhaka, Bangladesh.

4. Associate Professor, Department of Community Medicine, Z H Sikder Woman's Medical College, Dhaka, Bangladesh.

5. Associate Professor (C.C), Department of Community Medicine, Z H Sikder Woman's Medical College, Dhaka, Bangladesh.

6. Assistant Professor, Department of Community Medicine, Z H Sikder Woman's Medical College, Dhaka, Bangladesh

Corresponding author:

Shila Rani Das, Associate Professor, Department of Community Medicine, Z H Sikder Woman's Medical College, Dhaka, Bangladesh. Email:dr.shila@yahoo.com, Mobile - 01911183906 
to be different from each other. These may also vary from one geographical setting to another. ${ }^{9}$ In developing world, $1 / 3$ rd of all healthy adult women are lost due to reproductive health problem. ${ }^{10}$ Female population is about 60.26 million in Bangladesh and married women of reproductive age group constitute $51.7 \%$ of total female population. ${ }^{11}$ More than 500,000 women die every year due to pregnancy related complications in the developing world. ${ }^{12}$ Although the legitimate age at first marriage is 18 years for females and 21 years for males, rural females tend to marry even earlier. Approximately $75 \%$ of the girls are married before the age of 16 , and only $5 \%$ are married after 18 years ${ }^{13}$ The number of births attended by skilled health personnel is $13 \%$. and most of the deliveries takes place at home. ${ }^{14}$ The Government of Bangladesh seeks to create conditions whereby the people of Bangladesh have the opportunity to reach and maintain the highest attainable level of health and adopted the Health and Population Sector Strategy (HPSS) in 1998 to provide a package of essential health care services for the people and to slow down population growth..$^{15}$ The main sectorial objectives of the HPSS are: maintenance of the momentum of efforts in Bangladesh to lower fertility and reduce mortality, reduction of maternal mortality and morbidity and reduction in the burden of communicable diseases. ${ }^{16}$ The Health and Population Sector Program (HPSP) was formulated in 1998 on the basis of HPSS. In order to encompass all the activities of the health sector, the Government has revised the HPSP and formulated the new 'Health, Nutrition and Population Sector Program (HNPSP), 2003-2006. ${ }^{17}$ The vision and targets outlined in the Interim Poverty Reduction Strategy Paper (i-PRSP) of the government have been adopted as overarching longterm policy framework for HNPSP. ${ }^{18}$ The Programme of Action called upon countries to strive to make accessible through the primary health-care system, reproductive health to all individuals of appropriate ages as soon as possible, and no later than the year 2015. ${ }^{19}$

Material and methods: This cross sectional study of fifteen days' duration was conducted among Married women attending in OPD at Dhamrai Dhaka to know reproductive health practice of married women in the Rural Community with a sample size of 100 following purposive sampling technique using pretested semi-structured questionnaire by face to face interview method after taking informed consent. Data were analyzed manually and by using computer.

Result: Table I shows that About 39\% respondents were found within age of 20-30 years followed by $23 \%$ within $15-20$ years, $23 \%$ within 30 to 40 years and $14 \%$ respondents were within age group more than 40 years. About $33 \%$ respondents were complete primary education, $24 \%$ illiterate, $31 \%$ secondary, HSC \& above $12 \%$. Majority $(79 \%)$ of respondents were married followed by $13 \%$ widow and $8 \%$ divorce. Most of them $39 \%$ were housewives followed by $29 \%$ service holder, $21 \%$ day labor and major segment $(56 \%)$ had poor monthly income $(\mathrm{TK}<10,000)$.

Table 1: Sociodemographic characteristics of respondents $(\mathrm{n}=100)$

\begin{tabular}{|c|c|c|}
\hline Age in years & Frequency & Percentage \\
\hline $15-20$ years & 23 & $23 \%$ \\
\hline 20-30 years & 39 & $39 \%$ \\
\hline $30-40$ years & 23 & $23 \%$ \\
\hline$>40$ years & 14 & $14 \%$ \\
\hline \multicolumn{3}{|c|}{ Education } \\
\hline Illiterate & 23 & $23 \%$ \\
\hline Primary & 33 & $33 \%$ \\
\hline Secondary & 31 & $31 \%$ \\
\hline Higher secondary and above & 12 & $12 \%$ \\
\hline \multicolumn{3}{|c|}{ Marital status } \\
\hline Married & 79 & $79 \%$ \\
\hline Widow & 13 & $13 \%$ \\
\hline Divorced & 8 & $8 \%$ \\
\hline \multicolumn{3}{|c|}{ Occupation } \\
\hline Housewife & 39 & $39 \%$ \\
\hline Service holder & 29 & $29 \%$ \\
\hline Day labour & 21 & $21 \%$ \\
\hline Others & 11 & $11 \%$ \\
\hline \multicolumn{3}{|l|}{ Monthly Income } \\
\hline Less than 10,000 taka & 56 & $56 \%$ \\
\hline $1000-20000$ taka & 24 & $24 \%$ \\
\hline 20000-30000 taka & 12 & $12 \%$ \\
\hline Above 30000 taka & 8 & $8 \%$ \\
\hline Total & 100 & $100 \%$ \\
\hline
\end{tabular}

Table No. 2 describes respondents by duration of married life, age at first issue $\&$ number of children. Majority $(78 \%)$ of respondent's duration of married life less than or equal to 15 years and majority (72\%) respondents were found having their first issue at less than and equal to 25 years of age. About $40 \%$ respondents were found having two children and 33\% respondents were found having one child only. 
Table 2: Distribution of respondents by duration of married life, age at first issue \& number of children $(\mathbf{n}=\mathbf{1 0 0})$

\begin{tabular}{c|c|c}
\hline Duration of married life & Frequency & Percentage \\
\hline $\begin{array}{c}\text { Less than and equal or } 15 \\
\text { years }\end{array}$ & 78 & $78 \%$ \\
$\begin{array}{c}\text { More than 15 years } \\
\text { Age at first issue }\end{array}$ & 22 & $22 \%$ \\
Less than and equal to 25 & 72 & $72 \%$ \\
$\quad$ years & & \\
More than 25 years & 18 & $18 \%$ \\
\hline Number of Children & & \\
\hline 1 & 33 & $33 \%$ \\
2 & 40 & $40 \%$ \\
3 & 18 & $18 \%$ \\
4 & 9 & $9 \%$ \\
\hline Total & 100 & $100 \%$ \\
\hline
\end{tabular}

Table 3 shows that about $47 \%, 52 \% \& 25 \%$ respondents received advices on healthy diet, personal hygiene and cautions about drug uses respectively. Almost (84\%) of respondents were done USG followed by $67 \%$ were done $\mathrm{Hb} \%, 34 \%$ urine $\mathrm{R} / \mathrm{M} / \mathrm{E}$ and $21 \%$ blood grouping respectively.

Table 3: Distribution of respondents by antenatal advices \& investigations done during last delivery (Multiple response)

\begin{tabular}{ccc}
\hline Antenatal Advice & Frequency & Percentage \\
\hline Health diet & 47 & $47 \%$ \\
Personal hygiene & 52 & $52 \%$ \\
drug use & 25 & $25 \%$ \\
Warning sign & 15 & $15 \%$ \\
\hline Investigations done in last & & \\
pregnancy & & $84 \%$ \\
USG & 84 & $67 \%$ \\
Hb\% & 67 & $41 \%$ \\
HbsAg & 41 & $34 \%$ \\
Urine R/M/E & 34 & $21 \%$ \\
Blood grouping & 21 & $5 \%$ \\
Stool R/M/E & 5 & $2 \%$ \\
Chest X-ray & 2 &
\end{tabular}

*Multiple response

Figure 1 describe distribution of respondents by place of last delivery majority (65\%) of respondents delivered their last issue in hospital and 35\% delivered at homes.

\section{Place of delivery}

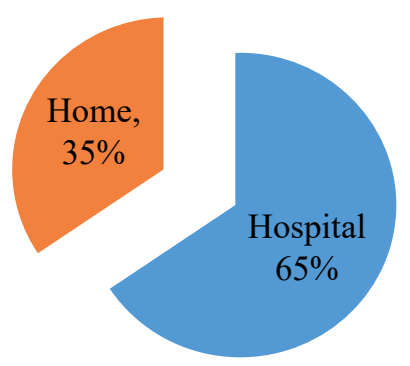

Figure 1: Distribution of respondents by place of last delivery

Figure 2 shows that About 55\% respondents last delivery conducted by qualified doctors followed by $25 \%, 10 \%$ and $10 \%$ untrained birth attendant, skilled birth attendant and nurses respectively.

\section{Personnel conducted delivery}

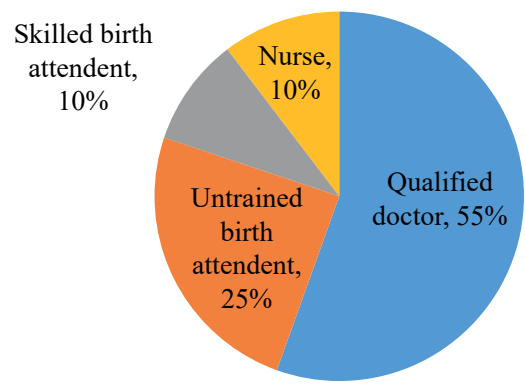

Figure 2 Distribution of respondents according to investigation of personnel by women their last delivery done $(n=100)$

Table No. 4 describe distribution of respondents' TT immunization, complications during last delivery \& problems related to reproductive system. Majority (85\%) respondent received TT immunization and 35\% did not receive any immunization. Majority (71\%) had no complication in last delivery and $29 \%$ respondents faced complications during last delivery and 53\% respondents were suffering from problems related to reproductive system and $47 \%$ had no problem. 
Volume 2, Number 1, January 2020

Table 4: Distribution of respondents' TT immunization, Complications during last delivery \&

Problems related to reproductive system $(n=100)$

\begin{tabular}{c|c|c}
\hline TT vaccination received & Frequency & $\begin{array}{c}\text { Percentage } \\
\text { (\%) }\end{array}$ \\
\hline Yes & 85 & $85 \%$ \\
No & 15 & $15 \%$ \\
\hline $\begin{array}{c}\text { Compilations during last } \\
\text { delivery }\end{array}$ & \\
\hline Yes & 29 & $29 \%$ \\
No & 71 & $71 \%$ \\
\hline $\begin{array}{c}\text { Problems related to } \\
\text { reproductive system }\end{array}$ & \\
\hline Yes & 53 & $53 \%$ \\
No & 47 & $47 \%$ \\
\hline
\end{tabular}

Figure 2 shows that abortion (35\%), PPH (30\%), perineal tear $(15 \%)$, neonatal convulsion $(10 \%)$, still birth $(9 \%)$ and hand prolapse $(2 \%)$ were the most common complications during last delivery.

\section{* Multiple response}

\section{Type of complication during last delivery}

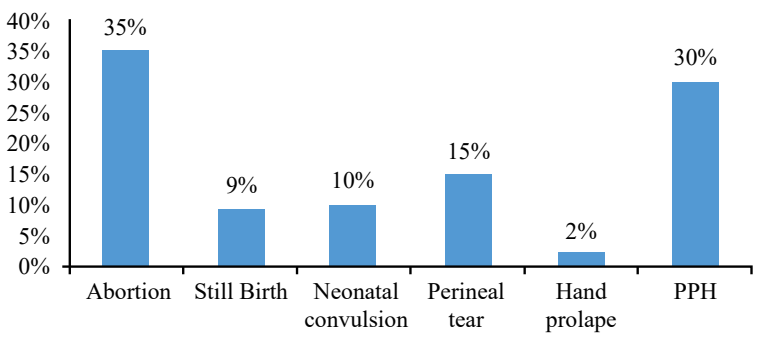

Figure No. 3: Distribution of respondents according to their type of complication during last delivery.

Discussion: The present study aimed to know Reproductive Health Practice of married women in the rural community. In this study about $39 \%$ were found within age of 20-30 years followed by 15-20 years (23\%), 30 to 40 years $(23 \%)$ and $\geq 40$ years $(14 \%)$ and about $33 \%$ respondents completed primary education and only $12 \%$ had education HSC and above. Majority $(79 \%)$ of respondents were married followed by widow and divorced $13 \%$ and $8 \%$ respectively. A completely dissimilar picture was observed by M Rahman where $86 \%$ of the respondents were found within the age group of $20-39$ years and $99 \%$ were married, whereas only $0.56 \%$, $0.38 \%$ were widow and divorced respectively; $33 \%$,
$39 \%$ \& 13\% completed Primary, Secondary and HSC level of education respectively. About $15 \%$ respondents were illiterate..$^{20}$ About 39\% were housewives followed by service holder (29\%), day labor $(21 \%) ; 56 \%$ had poor monthly income $(\mathrm{TK}<10,000)$. Almost similar finding was revealed by the Centre for Integrated Rural Development of Asia and Pacific where $82 \%$ of women in rural areas were found unpaid family workers. ${ }^{21}$ Majority (78\%) of respondent's duration of married life $\leq 15$ years and $72 \%$ respondents were found having their first issue at $\leq 25$ years of age and about $40 \%$ were found having 2 children and $33 \%$ had one child only. Similar finding was depicted through the survey of MOHFW where $75 \%$ of the girls were found married before the age of 16 . Because of early marriage majority $(69.8 \%)$ of the women had first child birth during adolescence (16-18 years) but the survey of MOHFW found that about $30 \%$ of female adolescents of Bangladeshi were already mothers. ${ }^{22}$ About $47 \%, 52 \%$ \& $25 \%$ respondents received advices on healthy diet, personal hygiene and cautions about drug uses respectively. Almost (84\%) of respondents done USG on their routine antenatal investigation. Majority (65\%) of respondents delivered their last issue at hospital. Relevant survey conducted by SVRS, BBS had different finding where home delivery was $87.1 \%{ }^{23}$ About $55 \%$ respondents last delivery conducted by qualified doctors. This finding varies with the finding of the survey of BDHS, which estimated $64.0 \%$ delivery conducted by untrained birth attendants. ${ }^{24}$ Almost (85\%) respondent received TT vaccine and $71 \%$ respondents last delivery faced without any complications and only $29 \%$ respondents faced complications. About $53 \%$ respondents suffered from problems related to reproductive system among them abortion (35\%), $\mathrm{PPH}$ $(30 \%)$ and perineal tear $(15 \%)$ were the most common complications during last delivery.

\section{Conclusion}

Women in rural Bangladesh are not empowered economically, social and their reproductive health rights are mostly neglected. Effective strategies and initiation must be taken to improve reproductive health status of the women in rural Bangladesh.

\section{References:}

1. Inter-agency Working Group on Reproductive Health in Crises. Inter-Agency Field Manual on Reproductive Health in Humanitarian Settings. Inter-agency Working Group on Reproductive Health in Crises, 2010.

2. Bangladesh Maternal Health Services and Maternal Mortality Survey 2001

3. Ahmed B. Differential Fertility in Bangladesh: A Path Analysis. Soci. Biol. 1982; 28(1-2): 102-110. 
Volume 2, Number 1, January 2020

4. Bangladesh Bureau of Statistics. 2001 Statistical year book of Bangladesh. 22nd ed. Bangladesh. 2001

5. Griffin S. Literature review on sexual and reproductive health rights: universal access to services, focussing on East and Southern Africa and South Asia. Panos, London: Department for International Development, 2006.

6. Adinew YM, Worku AG, Mengesha ZB. Knowledge of reproductive and sexual rights among University students in Ethiopia: institution-based cross-sectional. BMC International Health and Human Rights, 2013; 13:12.

7. The Fourth World Conference on Women. Beijing Declaration and Platform for Action Beijing, 4 to 15 September 1995.

8. Sexual and reproductive health and rights. Department for International Development, July 2004. Available from: http:// www.hivpolicy.org/Library/HPP000499.

9. Duncan OD. Path Analysis: Sociological Examples (Addenda). Casual Models in Social Science, Chicago, Aldine-Atherton Inc. 1977

10. Rashid KM, Rahman M, Hyder H. Textbook of Community Medicine and Public Health. MCH and Reproductive Health. 4th edition. RHM Publishers, Banani, Dhaka, Bangladesh; 2009.

11. Bangladesh Bureau of Statistics. Preliminary report 2001. Population Census of Bangladesh; 2002.

12. Effects of the Productive Role of Bangladeshi Women. Reported by Rebecca Sealand Katrina Manson, The Daily Independence, 13 March, 2009.

13. Report of Sample Vital Registration System (SVRS). Bangladesh Bureau of Statistics (BBS), Dhaka; 2004.

14. Bangladesh Bureau of Statistics (BBS). Sample Vital Registration System (SVRS), Bangladesh; 2008.

15. Coale AJ. The Demographic Transition". In the Population Debate- Dimensions and Perspectives. United Nations. 1975; Vol. 1.

16. Chowdhury SNM, Kabir M, Hossain A. MR Programme in Bangladesh: Challenges for the Future”. Background paper prepared for the project. A Situation Analysis of Bangladesh Menstrual Regulation Programme. Reproductive Health Alliance. 2002.

17. Mondal MNI, Hossain MK, Akter MsN. Reproductive health write of women in the Rural Area of Meherpur District in Bangladesh. J. Reprod. Infertility. 2010; 12(1): 23-32.

18. Bangladesh Maternal Health Services and Maternal Mortality Survey. National Institute of Population Research and Training (NIPORT), Ministry of Health and Family Welfare, ORC Macro, Calverton, Maryland, USA and Johns Hopkins University, USA. March 2002.

19. Save the Children. USA: Save the Children Federation; 2011. A Study on the Impact of the workshop on family planning conducted with the traditional and religious leaders in Nasir- nagar Thana. 1993 Sept 19 [cited 2011 Mar 18]. Available on: http://pdf.usaid.gov/pdf_docs/PNABU 648.pdf

20. *M Rahman, A Rahman, TT Sajoni, SA Chowdhury, A Akhter, Reproductive Health Practice of Married Women in the Rural Community of Dhamrai Upazila, Dhaka, AKMMC J 2013; 4(2): 31-36

21. Bangladesh Bureau of Statistics (BBS). Sample Vital Registration System (SVRS), Bangladesh; 2008.

22. Rashid KM, Rahman M, Hyder H. Textbook of Community Medicine and Public Health. MCH and Reproductive Health. 4th edition. RHM Publishers, Banani, Dhaka, Bangladesh; 2009

23. Family planning world wide datasheet 2002 , Washington D.C., Population Reference Bureau, 2002.

24. Bangladesh Bureau of Statistics. Preliminary report 2001. Population Census of Bangladesh; 2002 